\title{
As redes de apoio social nas práticas de educação popular e saúde:
}

\author{
reflexões de uma pesquisa-ação
}

Kátia Suely Queiroz Silva Ribeiro(a)

Eymard Mourão Vasconcelos ${ }^{(b)}$

Oliveira LC, Ávila MMM, Gomes AMA, Sampaio MHLM. Social support networks in practice of popular health education: reflections of an action-research. Interface (Botucatu). 2014; 18 Supl 2: 1453-1462.

Social support networks are crucial for people with disabilities of the lower classes. This study presents the route of an actionresearch, analyzing the social support networks of these people and findings related to learning research guided by the principles of Popular Education (PE). The study had two phases: interviews to map the social support networks, activation and mobilization of these networks. The first step found that isolation was a problem that these people experienced. Then there were meetings involving the various actors of the social network, both at personal and community levels. Various difficulties were encountered during this process and learning about the process as a result. $\mathrm{PE}$ was essential to understanding the difficulties and motivations of the subjects of the research, by guiding activities and helping to persist in actions and believing in the subjects ability to be more.

Keywords: Action-research. Health Education. Disabled persons.
As redes de apoio social têm importância fundamental para as pessoas com deficiência física das classes populares. Este trabalho objetiva apresentar o percurso de uma pesquisa-ação, analisando as redes de apoio social dessas pessoas e as constatações referentes ao aprendizado de uma pesquisa orientada pelos princípios da Educação Popular (EP). A pesquisa teve duas fases: entrevistas para mapear as redes de apoio social e ativação e mobilização dessas redes. Constatou-se, na primeira etapa, a problemática do isolamento em que viviam aquelas pessoas. Em seguida, foram realizadas reuniões envolvendo os diversos atores da rede social, tanto em nível pessoal, quanto comunitário. Várias dificuldades e aprendizados resultaram desse processo. A EP foi fundamental para compreender as dificuldades e motivações dos sujeitos da pesquisa, orientou as atividades e ajudou a persistir nas ações, acreditando na capacidade de ser mais destes sujeitos.

Palavras-chave: Pesquisa-ação. Educação popular. Pessoa com deficiência. 


\section{Introdução}

O projeto de extensão universitária denominado Fisioterapia na Comunidade desenvolve atividades em duas comunidades da periferia de João Pessoa, visando à promoção, manutenção da saúde e reabilitação, sob a perspectiva da Educação Popular.

A partir da inserção nestas comunidades e do acompanhamento ao processo de reabilitação dos seus moradores com deficiência, tornaram-se claras para nós as dificuldades que eles enfrentam face ao contexto sócioeconômico em que vivem. Também se evidenciaram as diversas formas de apoio que encontram, em maior ou menor escala, na família, entre os vizinhos, lideranças comunitárias e religiosas. Esses atores formam uma rede em torno das pessoas com deficiência e evidenciam a importância do apoio social em suas vidas. Destacam-se as diversas formas de apoio que esses sujeitos encontram, a partir de seus laços familiares, de amizade ou comunitários, tanto no que se refere à realização de suas atividades de vida diária quanto à ajuda em situações especiais. Forma-se, assim, uma rede de apoio social, que assume uma importância fundamental na vida das pessoas com deficiência física das classes populares, amenizando as limitações que enfrentam.

Os profissionais de saúde fazem parte dessa rede, podendo representar um elo de integração entre os diversos sujeitos que a compõem, aumentando a teia de relações que se estabelece entre as famílias e os moradores da comunidade.

Os pressupostos teórico-metodológicos da Educação Popular em Saúde (EPS) que orientam o trabalho nesse projeto de extensão indicam a importância de valorizarmos as iniciativas das pessoas da comunidade e o saber que elas detêm, contribuindo para que nós identifiquemos no apoio disponibilizado pelas pessoas próximas ao sujeito em tratamento, elementos importantes no sentido de superar as dificuldades encontradas. Compreendemos que o reconhecimento destas redes pode contribuir para o entendimento da real situação de saúde dessas pessoas, assim como proporcionar mudanças nas práticas de saúde.

O apoio social já vem tendo espaço no debate da EPS há alguns anos, a partir dos trabalhos de Victor Valla $a^{1,2,3}$. Constatamos que esse apoio, conquanto fosse utilizado nas práticas de EPS, não era reconhecido e valorizado, contribuindo para que seu potencial não fosse desenvolvido.

Partindo dessas considerações, propusemos analisar o significado da valorização das redes de apoio social nas práticas de Educação Popular em Saúde voltadas às pessoas com deficiência, incentivando a interação entre profissionais de saúde e as redes de apoio social, no sentido da construção de ações de saúde mais integrais para as pessoas com deficiência física. Nessa perspectiva, foi desenvolvida uma pesquisa, como parte dos estudos de doutorado do Programa de Pós-Graduação em Educação da Universidade Federal da Paraíba (UFPB).

Pretendemos, no presente trabalho, apresentar o percurso metodológico realizado nessa pesquisa, bem como as constatações referentes ao aprendizado resultante de uma pesquisa orientada pelos princípios da Educação Popular. Este artigo não pretende expor todos os resultados desta pesquisa, mas refletir, a partir desta experiência investigativa, estratégias e aprendizados significativos para a implementação de uma pesquisa orientada pela EPS na lógica da pesquisa-ação. Secundariamente, pretende apontar caminhos de uma ação educativa popular junto a pessoas com deficiência físicas em comunidades urbanas periféricas, bem como discutir o significado da valorização das redes de apoio social nas práticas de saúde.

\section{Metodologia}

Dentro da tradição de pesquisa em Educação Popular, têm sido muito valorizadas as modalidades metodológicas da pesquisa-ação, observação participante, pesquisa participante e sistematização de experiências, a exemplo do livro Educação Popular na Formação Universitária: reflexões com base em uma experiência ${ }^{4}$. A presente pesquisa orientou-se, principalmente, pela pesquisa-ação, a qual, de acordo com Thiollent ${ }^{5}$, é concebida e realizada em estreita associação com uma ação ou resolução de 
problema, estando os pesquisadores e participantes representativos da situação envolvidos de modo cooperativo ou participativo.

A pesquisa-ação constou de duas fases. A fase inicial objetivou mapear as redes de apoio das pessoas com deficiência, ao mesmo tempo em que possibilitou a construção de relatos sobre suas trajetórias de vida após a deficiência. Na segunda fase, ocorreu a ação propriamente dita, que constou da ativação e mobilização das redes de apoio social, através de reuniões, visitas domiciliares e contatos pessoais. Nessa fase, os dados foram registrados em um diário de pesquisa.

Sendo assim, nas atividades realizadas na pesquisa entrelaçaram-se a coleta de dados com a ação em curso, cuja finalidade era incentivar a interação entre os diversos elementos da rede social das pessoas com deficiência. Esse processo exigiu um cuidado mais acentuado no sentido de perceber e registrar não apenas as falas dos participantes, mas também seus silêncios, suas atitudes e gestos que, muitas vezes, contrastavam com os discursos proferidos.

A preocupação comum entre os pesquisadores referente à inserção no grupo social a ser estudado não representou problema nesta pesquisa, uma vez que já tínhamos um vínculo com aquela comunidade, em função do trabalho que desenvolvíamos nesse local há cerca de 10 anos na ocasião da realização da pesquisa. Não havia estranhamento com a nossa presença, pois já existia uma relação de confiança prévia. A análise dos dados foi um processo extremamente complexo. A quantidade de dados resultantes de entrevistas transcritas e registros no diário de campo exigiu muito esforço na ordenação dos mesmos. A primeira etapa constou de um processo de leitura e releitura de todo o material coletado. Em um segundo momento, o material foi ordenado em unidades de registro, as quais, de acordo com Minayo ${ }^{6}$ "podem ser uma palavra, uma frase, um tema, um personagem, um acontecimento".

Foram ordenadas, então, três unidades: as pessoas com deficiência e suas redes; a mobilização da rede social; e a interação entre as redes de apoio e o serviço de saúde na prática de EPS. Em cada uma dessas unidades foram selecionados temas, trabalhados com base em categorias de análise, algumas estabelecidas a priori com base no referencial teórico, outras foram "construídas de maneira indutiva, isto é, ao longo dos progressos da análise"7.

Em relação à primeira unidade de registro, foi realizado, inicialmente, o relato das histórias e a análise das redes sociais mapeadas. A partir daí, procedeu-se a uma análise das categorias decorrentes das constatações feitas nessa primeira etapa. No que diz respeito à segunda e à terceira unidades, foram trabalhados temas que se destacaram no processo de mobilização das redes de apoio social, distribuídos em categorias que emergiram nesse processo e que estavam relacionados à problemática proposta pela pesquisa. O instrumental teórico da Educação Popular norteou todo o processo de análise dos dados. Analisaremos neste artigo o percurso da pesquisa, as dificuldades e estratégias de superação encontradas, bem como os aprendizados metodológicos dela oriundos.

\section{Desenvolvimento da pesquisa}

\section{O cenário}

A pesquisa foi desenvolvida em um bairro da periferia de João Pessoa, tendo como local de referência as três Unidades de Saúde da Família (USF) desse bairro. Trata-se de um bairro que, como tantos outros das periferias das cidades, reúne características de área que foi destinada a ser residencial, contando com razoável infra-estrutura, como também de áreas de ocupação, nas quais as condições de moradia se tornam muito precárias. A maioria das pessoas com deficiência física moradoras desse bairro reside nas ruas que estão em piores condições, localizadas nas partes de baixo do bairro, cheias de grotas. Esse fato nos obrigou a conhecer de forma bem real as dificuldades que os moradores enfrentam com a precária situação de infraestrutura urbana, que tem consequências muito mais perversas para as pessoas com deficiência.

Existe no bairro uma associação comunitária fundada há mais de vinte anos, no entanto, não há envolvimento dos moradores enquanto associados. Registra-se, assim, uma fragilidade na organização 
comunitária desse bairro, uma vez que, além da associação, que não funciona, há um conselho comunitário que, na ocasião da pesquisa, estava em fase de discussão para implantação. Além disso, a relação dos moradores com os movimentos sociais se dá de forma pontual.

\section{Os participantes da pesquisa}

A pesquisa se deu em torno de pessoas com deficiência física acompanhadas pelo Projeto de Extensão Fisioterapia na Comunidade da UFPB, que realizavam atendimento fisioterapêutico. Todas as pessoas selecionadas e convidadas a participar adquiriram a deficiência na vida adulta. Todas elas foram esclarecidas, inicialmente, do objetivo do estudo e assinaram o Termo de Consentimento Livre e Esclarecido, sendo considerados os aspectos éticos e legais preceituados pela Resolução no 196/96 que trata de pesquisas envolvendo seres humanos.

Participaram da pesquisa dez pessoas com deficiência e suas famílias, além de profissionais das equipes de saúde da família, estudantes de Fisioterapia atuantes no projeto de extensão e um pastor, que é uma importante liderança na comunidade. Todas as dez pessoas tinham uma história anterior à deficiência, que se modificara drasticamente após esta. Ficou evidente a importância de se conhecer detalhadamente a história prévia dessas pessoas para melhor compreendê-las.

Os agentes comunitários de saúde foram os profissionais mais assíduos durante as atividades da pesquisa. Além deles, participaram das reuniões uma médica e duas enfermeiras das USF.

\section{Percurso inicial da pesquisa}

O primeiro passo para um trabalho com as redes de apoio social é identificar as redes das pessoas em torno de quem a ação será desenvolvida, a fim de lhes dar visibilidade e mobilizá-las. O conhecimento da rede social pessoal permite analisar a extensão das relações sociais da pessoa e, consequentemente, o nível de suas interações sociais, assim como identificar, na composição da rede, quem são as pessoas mais disponíveis para se envolver nas ações a serem realizadas. No decorrer do nosso trabalho naquela comunidade, já conhecíamos as lideranças ali existentes, as famílias das pessoas com quem convivíamos e vários moradores, mas não sabíamos exatamente qual era a relação que cada pessoa por nós acompanhada estabelecia com essas lideranças, com seus vizinhos, com outras pessoas com deficiência, etc. Procedemos, então, a essa primeira etapa da pesquisa, que constou do mapeamento das redes sociais pessoais e foi de grande valia para todo o processo educativo e de pesquisa.

Além de buscar conhecer as redes de apoio social das pessoas com deficiência física, a primeira fase da pesquisa também teve como finalidade construir um relato das trajetórias dessas pessoas após a deficiência. Para tanto, foram realizadas entrevistas semiestruturadas com cada uma delas e com um membro da família.

Tendo como base os objetivos da pesquisa, foram elaborados roteiros para cada grupo de entrevistados - pessoas com deficiência e familiares, profissional de saúde, pessoa-chave da rede estes roteiros serviram para nortear as entrevistas.

Em primeiro lugar, foram entrevistadas as pessoas com deficiência e seus familiares, seguidos das pessoas mais citadas como integrantes das redes de apoio. Após a realização de cada entrevista, era feito um registro das impressões que, além de contribuir como observação, serviu para ajustar esse instrumento. Assim, algumas questões propostas no roteiro foram sendo menos enfatizadas nas entrevistas seguintes, outras foram sendo acrescentadas, em função das descobertas e percepções que iam se desenrolando. Conforme assinalam Pope e Mays ${ }^{8}$, "o processo analítico começa durante a fase de coleta de dados, pois os dados já coletados são analisados e inseridos ou formatam a coleta de dados em andamento".

A partir das entrevistas, foi construído um mapa da rede pessoal, baseado no modelo de mapa de rede proposto por Dabas e Perrone ${ }^{9}$ e também referenciado por Sluzki ${ }^{10}$ e Klefbeck ${ }^{11}$. Nesse mapa, a rede social está dividida em quatro grupos: grupo 1- família; grupo 2 - amizades e vizinhos; grupo 3 - relações de trabalho e estudo; grupo 4 - relações comunitárias, de serviços e religiosas. Essa divisão é importante porque ajuda a visualizar quais grupos são mais fortes ou mais presentes na rede social. Foram realizadas vinte e duas entrevistas que foram gravadas e transcritas. 


\section{Seguimento das atividades da pesquisa}

Constatou-se nessa primeira etapa da pesquisa a problemática do isolamento em que vivem aquelas pessoas com deficiência. Cabia, na ação a ser empreendida, realizar atividades que pudessem impulsionar mudanças na situação verificada. Em nosso trabalho de Educação Popular e Saúde, sempre buscávamos contribuir com o processo de autonomia das pessoas com deficiência. Acreditávamos na capacidade de superação que elas tinham latente, na sua capacidade humana de ser mais, como aponta Freire $^{12}$, mas sentíamos a dificuldade de que elas próprias acreditassem no potencial de que eram possuidoras e buscávamos meios de incentivar que esse potencial viesse a aflorar.

Foi nesse sentido que planejamos os próximos passos da pesquisa, objetivando promover uma interação social das pessoas com deficiência e sensibilizá-las para o reconhecimento de seu potencial interior. Programamos, então, a realização de uma apresentação de dança e basquete do grupo de cadeirantes de uma Fundação que presta assistência a pessoas com deficiência na cidade. A apresentação aconteceu em uma escola pública municipal.

Percebemos, durante a apresentação, que algumas pessoas com deficiência estavam sentadas nas filas de trás. Constatamos que elas fizeram questão de que fosse assim, pois se sentiam envergonhadas. Aquela era a primeira vez que os moradores daquele bairro viam tantas pessoas com deficiência, da comunidade, reunidas. Era também a primeira vez que algumas dessas pessoas se expunham publicamente. Aquela primeira ação da pesquisa já causara um impacto, tanto nas pessoas com deficiência e seus familiares, quanto nos moradores da comunidade que foram assistir. Naquela ocasião, a ação educativa que se propunha a ser dirigida às pessoas com deficiência, revelou-se uma oportunidade educativa também para os demais moradores. Assistindo à apresentação, elas tiveram a oportunidade de perceber que as pessoas com deficiência são capazes de superar seus limites e também puderam conhecer pessoas com deficiência moradoras da comunidade. A diretriz metodologia da EP, de incentivar a articulação de grupos locais com movimentos e instituições mais gerais, mostrou-se muito importante.

Para dar seguimento às atividades da pesquisa, foram programadas reuniões que denominamos de reuniões com os atores das redes sociais. Nos períodos que antecederam as reuniões, assim como nos intervalos de tempo entre sua realização, aconteceram visitas às casas das pessoas envolvidas na pesquisa e outras atividades que surgiram como desdobramento das reuniões. Todos os fatos e impressões relacionados com a pesquisa foram registrados no diário de pesquisa, que constituiu, juntamente com as entrevistas, os principais instrumentos de coleta de dados dessa pesquisa. Foram nove meses de registros de observação e reflexões.

\section{Reunindo os diversos atores das redes sociais}

O trabalho com grupos tem uma importância central na prática de EPS, tanto no sentido de que a diversidade de atores torna a ação educativa mais rica, quanto pelo valor dessa atividade no sentido de estimular a participação e a organização comunitárias.

A proposta de realizar reuniões envolvendo as redes sociais das pessoas com deficiência baseava-se na nossa experiência anterior de EPS e buscava fortalecer as ações de apoio que os sujeitos da rede social realizavam de forma pontual e desarticulada. Também tinha como referência teórica o trabalho realizado por Sluzki ${ }^{10}$. Esse autor analisa a interface indivíduo/família/inserção social, apontando para a necessidade de incorporarmos em nossos modelos e prática clínica cotidiana as dimensões da rede social pessoal dos usuários.

A proposta de Sluzki, que ele denomina intervenção terapêutica em rede, aproxima-se de alguns dos pressupostos que orientam as práticas de EPS, onde buscamos, através do diálogo com a população, conhecer a raiz dos problemas e encontrar soluções conjuntas. Sluzki argumenta que o envolvimento das redes pessoais de seus usuários é importante tanto no sentido de alcançar uma melhor compreensão do processo de adoecimento, quanto na busca de soluções para os problemas enfrentados. Essa intervenção pressupõe a materialização e mobilização das redes, desde a ativação de redes naturais até a geração de novas redes e, muitas vezes, a estimulação das habilidades necessárias para desenvolvê-las.

Decidimos, então, fazer uma reunião com todos os participantes das redes sociais identificadas para ouvir suas colocações, necessidades e, a partir daí, planejar as próximas reuniões. Esse é um percurso 
metodológico próprio da Educação Popular, isto é, adequar a metodologia às necessidades que surgem no processo e às demandas dos atores envolvidos.

A partir dessa reunião, resolvemos manter as reuniões com os atores das redes de apoio social conjuntamente. Era difícil precisar se, ao mobilizar as redes pessoais em conjunto, estávamos formando um coletivo de redes pessoais, uma rede coletiva, uma rede de redes pessoais ou uma rede comunitária. De acordo com Maffesoli ${ }^{12}$, a rede de redes não remete a um espaço onde os diversos elementos se adicionam, se justapõem, onde as atividades sociais se ordenam conforme uma lógica da separação, mas, antes, remete a um espaço onde tudo isso se conjuga, se multiplica formando figuras caleidoscópicas de contornos cambiantes e diversificados. Esse coletivo ganha força política e, consequentemente, poder de reivindicação, sendo um espaço de organização social.

Apresentava-se, assim, como uma possibilidade para as ações coletivas daquelas pessoas e também como forma de estabelecer nova esfera de convivência social, uma vez que aquelas pessoas com deficiência estavam fora dos espaços de trabalho e escolares, seus laços sociais eram bastante restritos e mantidos, principalmente, na família.

Ademais, as discussões em grupo possibilitam descobertas e proposições dificilmente alcançadas individualmente. Do diálogo que se estabelece quando um grupo se reúne para discutir um determinado assunto ou problema costumam surgir idéias novas, que antes não haviam ocorrido aos participantes. É o que passou a ocorrer nas reuniões com as pessoas das redes de apoio: a discussão do grupo possibilitou uma compreensão alargada do problema e também o surgimento de novas proposições. Esse é um jeito próprio do trabalho com Educação Popular (EP), no qual o processo educativo vai sendo delineado no decorrer do mesmo. O trabalho de mobilizar pessoas, incentivar a formação de grupos, contribuir com a organização comunitária e com o fortalecimento e a valorização das iniciativas e saberes dos atores sociais constitui a essência da prática de EP.

No decorrer das reuniões, a dimensão política daquele trabalho se evidenciou na perspectiva da organização coletiva em torno de questões comuns que demandavam o envolvimento de níveis institucionais da rede social.

A metodologia que adotávamos nas reuniões seguia os princípios da EPS, que havíamos incorporado à nossa prática. Traçávamos um objetivo, mas a pauta dos encontros surgia das demandas apresentadas nas reuniões. Em todos os momentos procurávamos nos colocar na condição de facilitadores do grupo, buscando criar espaços de diálogo, onde as pessoas pudessem expor suas opiniões, respeitando e acolhendo as sugestões, seguindo o ritmo dos componentes que compunham aquele coletivo. Ao final das reuniões, o grupo distribuía as tarefas definidas para as próximas reuniões entre os participantes. Respeitar as iniciativas dos atores faz parte de toda prática de EP e era natural para nós deixar a reunião fluir de acordo com a demanda do grupo e a discussão ser conduzida por eles. Isso redundou em momentos extremamente ricos de interação social e aprendizado para todos nós.

No decorrer das reuniões foram discutidas questões mais gerais, como a questão da acessibilidade, relacionada à precariedade das ruas e becos, mas também houve momentos em que complexas dimensões da vida pessoal foram abordadas. A intimidade das famílias acompanhadas era marcada por dinâmicas de opressão e desorganização que nos surpreenderam pela magnitude. Sem o conhecimento destas dinâmicas, o trabalho educativo não pode prosseguir com profundidade.

Ao longo desse percurso fomos ajustando a proposta, driblando as dificuldades que se apresentavam, ampliando a rede social daquele grupo e aprendendo com as pessoas e com a experiência que vivenciávamos.

\section{Vivenciando as dificuldades e aprendendo com elas}

As dificuldades surgidas ao longo da pesquisa foram de várias ordens. A primeira delas era a falta de um espaço de convivência comunitária que pudéssemos utilizar para realizar essas atividades grupais. Para que essa dificuldade fosse contornada precisávamos da colaboração das pessoas que eram responsáveis pelos espaços potencialmente disponíveis, mas, ao final, realizamos as reuniões no quintal 
da casa de uma das pessoas com deficiência da comunidade. A busca de espaço para a reunião ia deixando clara e pública a carência de infraestrutura para organização comunitária naquele bairro.

Outra dificuldade importante com que nos deparamos foi a insuficiência e, em alguns casos, a falta de apoio da família no sentido de possibilitar a participação das pessoas com deficiência nas reuniões. A possibilidade de ir às reuniões representava, em nossa visão, uma oportunidade para que essas pessoas pudessem sair de seu isolamento e também fazer um trabalho terapêutico.

Devido às dificuldades de transportar as pessoas para participarem das reuniões, particularmente daquelas cujas famílias não se dispunham a apoiá-las nesse sentido, assumimos a tarefa de transportá-las para o local da reunião. Acreditávamos que o trabalho de transportá-las assumido por nós, que não era nada pequeno naquelas ruas extremamente íngremes, esburacadas e sem pavimentação, seria recompensado com o prazer que elas sentiriam pela oportunidade de sair de casa.

Assim sendo, não foi fácil lidar com a frustração que inicialmente nos acometeu. Percebemos que não teríamos como única resistência a ser vencida o tremendo esforço de carregar as pessoas em suas cadeiras de roda por ladeiras e buracos, todas as vezes que havia reunião. Percebemos que o problema era mais complexo.

Imaginávamos que a família, ao se sentir apoiada por nós, teria mais disponibilidade de levar as pessoas com deficiência para atividades fora do domicílio. Isso de fato ocorreu com algumas famílias, havendo uma interação entre o nosso apoio e o da família. Outras pessoas, ao contrário, transferiram a responsabilidade para nós, encontrando ali uma oportunidade de aliviar sua carga e aproveitar algum tempo para si mesmas. Ficou claro para nós que levar as pessoas para a reunião representava para algumas famílias uma sobrecarga a mais em suas vidas e elas não estavam dispostas a assumir mais esse trabalho.

Podíamos e estávamos tentando apoiar a família, ajudar no que fosse possível, mas não podíamos nos encarregar totalmente da tarefa. O objetivo era que fizéssemos parte da rede, apoiando de forma mais consistente, mas isso não exime a família de sua responsabilidade. Assumir sozinhos esta tarefa não ajudaria no processo de fortalecimento das redes locais de apoio.

A despeito do desânimo que muitas vezes nos acometia, as reflexões feitas acerca do contexto daqueles sujeitos e o aprendizado que obtínhamos a partir daí nos ajudavam a seguir acreditando que as possibilidades que vislumbrávamos com aquele grupo eram capazes de superar as dificuldades enfrentadas. A EP foi fundamental nesse processo, ajudando-nos a perceber e lidar com dimensões da ordem do imaginário e do simbólico, que ficavam escondidas pelo preconceito e pela diferença cultural ${ }^{14}$, bem como pelas convicções que estavam arraigadas em nós. Ela nos ajudava a resistir ao desânimo mediante todas aquelas dificuldades e a aprender com elas. Também nos orientava no sentido de não cairmos em atitudes paternalistas e assistencialistas.

\section{Trabalhando na tessitura da rede - buscando ampliá-la e estimular a interação social}

Uma das atividades que buscamos desenvolver no decorrer da pesquisa foi articular as ações que os atores das redes de apoio desenvolviam isoladamente ou de forma fragmentada. Essa articulação poderia trazer uma ampliação nas possibilidades de interação social desse grupo e encontrar saídas para os problemas que emergiam.

Havia uma dimensão política nessa atividade, que se revelava no compromisso que um trabalho de EPS assume em favor dos sujeitos das classes populares. Nesse sentido, o incentivo à interação entre as pessoas com deficiência e suas redes de apoio social, visava, além de retirá-las do isolamento, encorajá-las a uma organização social. Podia ser também uma forma de fortalecer a organização comunitária ainda incipiente naquele bairro. Era necessário, portanto, não apenas articular os atores envolvidos, mas também mobilizar novos atores, ou seja, tecer de modo a incluir novos nós na rede.

Como desdobramento das reuniões, foi decidido convidarmos o representante do Núcleo de Pessoas com Deficiência (NPD) da prefeitura municipal que também fazia parte de uma associação de pessoas com deficiência. No primeiro contato com as pessoas da pesquisa, ele ficou bastante impressionado com as dificuldades de deslocamento enfrentadas pelas pessoas com deficiência naquele bairro. A despeito do fato de também ser uma pessoa com deficiência física, as dificuldades enfrentadas pelas 
pessoas daquela comunidade pareciam surpreendê-lo. A surpresa demonstrada por ele evidenciava a distância entre os representantes dos movimentos sociais de pessoas com deficiência, da realidade desse grupo de pessoas residentes nas periferias urbanas, especialmente daquelas cuja deficiência oferece maiores restrições em termos de deslocamento, já que esse não é, usualmente, o tipo de pessoa com deficiência que participa das associações.

Durante a reunião, o representante do NPD chamou a atenção para a necessidade de se organizarem, de terem propostas bem elaboradas, salientando que todas as conquistas são resultantes da organização coletiva. A presença dele trazia para o grupo uma nova representação, tanto institucional, do ponto de vista de seu papel enquanto representante do governo municipal, quanto em relação ao movimento social do qual fazia parte. A rede se ampliava para um nível macrossocial.

A perspectiva que se delineava era de que os componentes daquelas redes sociais poderiam se articular para formar um movimento social ou se inserir em um movimento já existente. Por outro lado, a idéia de rede também pode contribuir no sentido de articular os movimentos sociais, formando redes de movimentos.

Atualmente, alguns autores partem da hipótese de que é nas articulações entre organizações e atores políticos e nas subsequentes criações de redes que vêm se constituindo um movimento social. Melucci ${ }^{15}$ define movimento social como uma forma de ação coletiva baseada na solidariedade, desenvolvendo-se a partir do enfrentamento de um conflito e rompendo os limites anteriores do sistema em que ocorre a ação. No cenário atual, esse autor prefere falar de redes de movimento ou de áreas de movimento, nas quais inclui não apenas as organizações formais, mas também a rede de relações informais que conectam núcleos de indivíduos e grupos a uma área de participação mais ampla. Afirma, ainda, que as redes são formadas por pequenos grupos imersos na vida cotidiana com fins específicos, e caracterizam-se pela associação múltipla, pela militância parcial e efêmera, e pelo desenvolvimento pessoal e solidariedade afetiva como condições para participação.

Para que as redes atuem em uma perspectiva de movimento social é preciso que os diversos atores se articulem em torno de uma questão e encaminhem suas reivindicações. Era o que estava se processando nas nossas reuniões de rede. Através da rede estávamos articulando as pessoas com deficiência com o movimento social ao qual poderiam se vincular.

Constata-se, assim, que a intervenção com as redes sociais pode representar uma importante forma de participação e de mobilização coletivas. Elas são espaços férteis para uma ação em forma de movimento social ou de articulação com um movimento já instituído, trazendo-o para a rede, ampliando-a.

As ações de EPS costumam ocorrer tanto em nível das relações individuais, abordando questões subjetivas, quanto em nível coletivo, organizando as reivindicações e fortalecendo os grupos sociais. A ação que estávamos empreendendo com aquele grupo tinha essas duas dimensões, mas revelava-se mais fortemente na direção da organização do coletivo e sua articulação com movimentos sociais.

A partir do contato com o representante do NPD, surgiu a proposta de articulação com uma associação de pessoas com deficiência da cidade. Foi marcada uma reunião, mas as pessoas dessa entidade não compareceram. Talvez aqueles representantes da associação não tenham tido ideia do prejuízo em termos de credibilidade da associação e em termos de potencialidade da expansão do movimento em direção às pessoas com deficiência que não conseguem chegar aos centros de reabilitação ou participar de encontros e movimentos destinados a esse grupo.

Havia uma ação educativa para todos os envolvidos no processo. Para os representantes de uma associação de pessoas com deficiência, seria um aprendizado organizar o movimento para as pessoas que não conseguem chegar até ele, ajudando a despertar o potencial de participação política daqueles sujeitos. Mas, ao que parece, a institucionalização do movimento social restringe seu raio de ação, não havendo propostas de atuação no sentido exposto acima. Essa limitação do movimento não contribui de forma alguma com a inclusão das pessoas com deficiência mais limitadas fisicamente e que residem nas periferias urbanas, reforçando a condição de isolamento social ao qual elas estão submetidas e mantendo a distância que existe entre essas pessoas e os movimentos que dizem representá-las e pelos quais elas se sentem abandonadas. 


\section{Considerações finais}

Nessa pesquisa-ação foi colocada em prática uma proposta de Educação Popular em Saúde, tendo como principal instrumento metodológico o trabalho com as redes de apoio social. Por um lado, representa uma pesquisa-denúncia, ressaltando como as políticas sociais no âmbito das instituições públicas ainda são insuficientes para suprir as necessidades dos sujeitos das classes populares e também a frouxidão dos laços dos movimentos sociais, particularmente das organizações de pessoas com deficiência para com os sujeitos que vivem nas periferias urbanas. Mas é também uma pesquisa-proposição, na medida em que buscou apontar pistas, estratégias, metodologias, ideias e conceitos.

A Educação Popular foi o fundamento a partir do qual o trabalho se constituiu. Norteando nossa práxis, facilitou na busca de compreensão das dificuldades e motivações dos sujeitos da pesquisa, orientou o desenvolvimento das atividades e nos ajudou a perseverar, persistir nas ações propostas, por acreditarmos nesses atores, em suas potencialidades.

Sua relevância também se evidenciou pelo fato de que o conceito de rede social ajuda a legitimar ações que sempre permearam as práticas de Educação Popular em Saúde, trazendo para esse campo a discussão acumulada na sociologia em torno desse conceito. Permite, assim, conceituar, dar visibilidade, debater teoricamente uma questão que, mesmo sendo usual na prática de EPS e fazendo parte de sua lógica de atuação (protagonismo e interação dos atores sociais, diálogo entre saberes distintos, consolidação da autonomia), ainda não tem muita ênfase teórica nesse campo. Acrescenta-se a isso, o entendimento de que a incorporação das redes de apoio social nas práticas de saúde possibilita a realização de ações mais integrais.

Ao reconhecer a importância das redes de apoio social no trabalho em saúde, dar visibilidade a elas, e incorporá-las aos processos de cuidar da saúde, certamente se potencializam as ações desenvolvidas na perspectiva da EPS. O trabalho mais articulado e sistemático com os diversos atores que compõem as redes sociais, fazendo sobressair a participação de atores que nem sempre têm destaque no cenário social, pode ampliar as práticas de EPS, fortalecendo as iniciativas desses atores, conferindo-lhes mais força política. Por outro lado, e de forma complementar, a EP é um importante facilitador do trabalho com as redes sociais, contribuindo para que o profissional de saúde, inserido na rede social dos usuários, tenha uma postura de abertura ao diálogo, pautada no respeito às diferenças e na valorização do saber popular, pré-requisitos essenciais do trabalho com os diversos e diferentes atores que compõem a rede social. A Educação Popular pode contribuir para superar a fragmentação das redes de apoio social, potencializando sua ação e impulsionando para que elas se articulem com outros níveis da rede, a exemplo dos movimentos sociais.

Reunir os diversos sujeitos que compõem as redes sociais não é suficiente para garantir o protagonismo desses atores. Destaca-se o valor do trabalho com as redes inserido em uma prática de EPS, no sentido de contribuir com o restabelecimento da autoconfiança e o resgate da autoestima, na medida em que nessa prática se reconhece o valor dos saberes de experiência feitos, como nos diz Freire ${ }^{16}$, incorporando-os ao processo terapêutico, proporcionando a essas pessoas um sentido de pertencimento e reconhecimento sociais. Ademais, o incentivo à prática da solidariedade em circulação na rede possibilita o fortalecimento dos laços sociais.

\section{Referências}

1. Valla VV. Apoio social e saúde: buscando compreender a fala das classes populares. In: Costa MV, organizador). Educação popular hoje. São Paulo: Loyola; 1998. p. 151-79.

2. Valla VV. Educação popular, saúde comunitária e apoio social numa conjuntura de globalização. Cad Saúde Pública. 1999;15 Sup. 2:7-14. http://dx.doi.org/10.1590/S0102-311X1999000600002 
3. Valla VV. Redes sociais, poder e saúde à luz das classes populares numa conjuntura de crise. Interface (Botucatu). 2000;4(7):37-56. http://dx.doi.org/10.1590/S1414-32832000000200004

4. Vasconcelos EM, Cruz PJSC, organizadores. Educação popular na formação universitária: reflexões com base em uma experiência. São Paulo: Hucitec; 2011.

5. Thiollent M. Metodologia da pesquisa-ação. 7a ed. Rio de Janeiro: Record; 1993.

6. Minayo MCS. O desafio do conhecimento: pesquisa qualitativa em saúde. $5 a$ ed. São Paulo: Hucitec; 1998. p. 210.

7. Laville C, Dionne J. A construção do saber: manual de metodologia de pesquisa em ciências humanas. Porto Alegre: Editora Artes Médicas; 1999. p. 219.

8. Pope C, Mays N. Pesquisa qualitativa na atenção à saúde. 2a ed. Porto Alegre: Artmed; 2005.

9. Dabas E, Perrone N. Redes en salud. 1999 [acesso em: 4 abr. 2005]. Disponível em: $<$ http://www.pasteur.secyt.gov.ar/formadores/redsal-Dabas-Perrone>

10. Sluzki CE. A rede social na prática sistêmica - alternativas terapêuticas. São Paulo: Casa do Psicólogo; 1997.

11. Klefbeck J. Los conceptos de perspectiva de red y los métodos de abordaje em red. In: Dabas E, Najamnovich D, organizadores. Redes: el linguaje de los vínculos - hacia la reconstrucción y el fortalecimiento de la sociedad civil. Buenos Aires: Paidós; 2002. p. 345-72.

12. Freire P. Pedagogia do oprimido. 5a ed. Rio de Janeiro: Paz e Terra; 1978.

13. Maffesoli M. O tempo das tribos: o declínio do individualismo nas sociedades de massa. 2a ed. Rio de Janeiro: Forense Universitária; 1998.

14. Vasconcelos EM. Educação popular e a atenção à saúde da família. São Paulo: Hucitec; 1999.

15. Melucci A. Acción colectiva, vida cotidiana y democracia. 1999 [acesso em: 25 abr 2005]. Disponível em: https://pt.scribd.com/doc/63849814/36039728-ACCIONCOLECTIVA-Vida-Cotidiana-y-Democracia-Melucci

16. Freire P. Pedagogia da esperança: um reencontro com a pedagogia do oprimido. 10a ed. Rio de Janeiro: Paz e Terra; 2003.

Oliveira LC, Ávila MMM, Gomes AMA, Sampaio MHLM. Redes sociales de apoyo en la práctica de la educación popular y en la salud: reflejos de una investigación-acción . Interface (Botucatu). 2014; 18 Supl 2: 1453-1462.

Las redes sociales de apoyo son fundamentales para personas de las clases bajas con discapacidad física. Este trabajo presenta la ruta de la investigación-acción, el análisis de las redes de estas personas y las conclusiones del aprendizaje de una investigación orientada por el Principio de la Educación Popular (EP). El trabajo tuvo dos etapas: entrevistas, para mapear las redes de apoyo social y la activación y movilización de estas redes. En la primera etapa había el problema del aislamiento de estas personas. En seguida, hubo reuniones con los actores de la red social, tanto a nivel personal cuanto comunitario. En los resultados de este proceso hubo aprendizajes y dificultades. La EP fue esencial para comprender las dificultades y motivaciones de las personas, guió las actividades y ayudó a persistir en acciones, creyendo en la mayor capacidad de estas personas.

Palabras clave: Investigación-acción; Educación Popular; Personas con discapacidad. 